\title{
Microbiological and chemical monitoring of Marsala base wine obtained by spontaneous fermentation during large-scale production
}

\author{
Nicola Francesca $\cdot$ Ciro Sannino $\cdot$ Luca Settanni • \\ Onofrio Corona • Ettore Barone • Giancarlo Moschetti
}

Received: 3 July 2013 / Accepted: 9 January 2014 /Published online: 30 January 2014

(C) Springer-Verlag Berlin Heidelberg and the University of Milan 2014

\begin{abstract}
The present work was undertaken to evaluate the effect of natural wine making on the microbial and chemical composition of Marsala base wine. To this purpose, a largescale vinification process of Grillo grape cultivar was monitored from the grape harvest to the final product. Total yeasts (TY) showed a rapid increase after must pressings and reached values that were almost identical to those registered during conventional wine makings. Lactic acid bacteria (LAB) were registered at the highest levels simultaneous to those of yeast growth at the beginning of the process. Saccharomyces cerevisiae was the species found at the highest concentrations in all samples analysed. Several strains $(n=16)$ was registered at high levels during the alcoholic fermentation (AF) and/or aging of the wine; only two of them were detected on the grape surface. Lactobacillus plantarum was the LAB species most frequently isolated during the entire vinification process. The ethanol content was approximately $14 \%(\mathrm{v} / \mathrm{v})$ at the end of vinification. The $\mathrm{pH}$ value did not greatly vary during the process, and the volatile acidity (VA) was detected at low concentrations during the entire transformation. The concentration of malic acid rapidly decreased during the AF; on the other hand, lactic acid showed an irregular trend during the entire process. Trans-caffeoyl tartaric acid was the most abundant hydroxycinnamoyl tartaric acid, and volatile organic compounds (VOC) were mainly represented by isoamylic alcohol and isobutanol.
\end{abstract}

Keywords Grillo grape cultivar · Lactic acid bacteria .

Lactobacillus plantarum $\cdot$ Marsala base wine $\cdot$ Saccharomyces cerevesiae - Yeasts

N. Francesca $\cdot$ C. Sannino $\cdot$ L. Settanni $\cdot$ O. Corona $\cdot$ E. Barone $\cdot$ G. Moschetti $(\bowtie)$

Department of Agricultural and Forest Science, Università degli Studi di Palermo, Viale delle Scienze 4, 90128 Palermo, Italy

e-mail: giancarlo.moschetti@unipa.it

\section{Introduction}

The natural wine making process relies on spontaneous fermentation without the addition of any chemical compounds or microbial starters. In these conditions, the biodiversity of the fermenting microorganisms, mainly yeasts and lactic acid bacteria $(\mathrm{LAB})$, and the final quality of the resulting wine is considered to be quite unpredictable. However, several works have shown the positive effects of spontaneous fermentations on the organoleptic complexity of wine as a consequence of the growth of different species and/or strains together at high levels (Le Jeune et al. 2006; Wondra and Boveric 2001).

Modern oenology commonly uses commercial starter cultures in order to ensure a controlled fermentation. Even though the starter cultures are subjected to ad hoc selection for fermentation, they may not be able to compete with the indigenous inhabitants of the musts and cannot dominate the vinification process (Fleet 2008). The surviving microorganisms seem to be better adapted to the environmental conditions of a given wine producing area (Francesca et al. 2010; Suzzi et al. 2012), as well as to the cellar where the transformation takes place (Guzzon et al. 2011). Moreover, the composition of indigenous populations present in must may change during different vintages, since they are affected by the climatic conditions and/or agronomic practices (Fleet 2008). Furthermore, the cellar environment seems to be a source of microorganisms involved in spontaneous wine fermentation (Fleet 2008; Guzzon et al. 2011). From this perspective, a recent work demonstrated the role of cellar air in the wine yeast ecosystem (Ocón et al. 2013). That work also showed that the air surrounding different zones of the cellars were characterized by different concentrations and species of wine yeasts.

In general, the diversity of the microbiota during wine fermentation is inversely affected by the addition of oenological adjuvants. Recently, the request for wines with unique 
style is on the increase (Settanni et al. 2012a). Also, the demand of special wines, such as Marsala, Porto, Madeira, and Sherry, follows this trend. Marsala is the first Italian wine that enjoyed a controlled designation of origin (CDO) status. The technology of production of this special wine involves a base wine and the addition of cooked and/or concentrated and/ or fortified grape musts, and/or wine ethanol (D.P.R. 17 1987); after a long aging in a barrel, the mature Marsala wine must contains at least $17 \%(\mathrm{v} / \mathrm{v})$ ethanol. The Grillo cultivar is the grape variety mostly cultivated in Sicily to produce the base wine for Marsala (Settanni et al. 2012a).

A first work on yeast ecology associated to the Grillo grapevine cultivated within the Marsala wine area was already carried out by our group (Settanni et al. 2012a). Sicily represents one of the most important areas of Europe in terms of wine production, and the study of its wild yeast population could be relevant to improving the quality of its final product. Settanni et al. (2012a) also worked to select autochthonous S. cerevisiae strains with oenological aptitude for Marsala wine production. A wine starter strain collection obtained from a given area could be useful for local winemakers who want to produce wines with regional features and, at the same time, ensure the correct fermentation process. Several researches have been focused on the technological selection of yeasts in different wine areas throughout the world (Ocón et al. 2010) with the aim to satisfy the increasing demand for wines with a specific organoleptic profile.

In this context, a study of yeasts and LAB ecology during unconventional processes such as natural wine making could provide enhanced opportunities for products with unique characters (Fleet 2008) that sought after for these qualities, such as Marsala wines.

For these reasons, the objectives of the present study were to evaluate the microbiological, chemical, and sensorial features of Marsala base wine during a large-scale wine making process created with the Grillo cultivar under natural conditions.

\section{Materials and methods}

Wine making process and sample collection

In order to evaluate the effects of natural wine making on the microbiological and chemical features of Marsala base wine, white grapes of the Grillo variety were subjected to the vinification process following spontaneous fermentation during the vintage 2010. The grapes were cultivated in the Marsala wine area $\left(37^{\circ} 35^{\prime} 29.35^{\prime \prime}+12^{\circ} 46^{\prime} 31.09^{\prime \prime}\right)$ and the transformation process was carried out at the winery "Azienda Agricola Antonino Barraco" (Marsala, TP, Italy).

The vinification was carried out in duplicate: 40 quintals of grapes for each trial were manually harvested and subjected to stemmer-crushing. The musts were transferred to stainless steel vats ( $50 \mathrm{hL}$ volume) where alcoholic fermentation $(\mathrm{AF})$ was driven by the yeasts present on the grape surface and/or in the winery environment. Sulphites were not added.

After $48 \mathrm{~h}$ of crushing, a maceration of must was applied: the liquid phase was in contact with the skin and seeds at a constant temperature of $17^{\circ} \mathrm{C}$ for $48 \mathrm{~h}$. At the end of maceration, the bulk must of each vat was subjected to a hydraulic pressing and the liquid phase was transferred into stainless steel tanks ( $25 \mathrm{hL}$ volume). The fermentation continued at a controlled temperature of $20{ }^{\circ} \mathrm{C}$ and the sugar consumption was monitored daily. Subsequently, the liquid mass was subjected to aging in steel vats at $20^{\circ} \mathrm{C}$.

Five hundred grape berries collected before crushing, samples of must during fermentation, and wine samples collected until the end of the aging process were all used to perform the microbiological and chemical analyses.

\section{Microbiological analysis}

To collect the microorganisms hosted on the peel surface, the grape berries were placed into sterile plastic bags containing a washing isotonic peptone solution $(10 \mathrm{~g} / \mathrm{L}$ Bacto Soytone, $2 \mathrm{~mL} / \mathrm{L}$ Tween 80 ) and incubated at $30{ }^{\circ} \mathrm{C}$ for $3 \mathrm{~h}$ (Renouf et al. 2005). All cell suspensions form grapes, must, and wine were subjected to a decimal serial dilution in Ringer's solution (Sigma-Aldrich, Milan, Italy). The surfaces of cellar equipment were analysed following the methodology ISO (2004). The microorganisms were cultivated as follows: TY were spread plated $(0.1 \mathrm{~mL})$ onto Wallerstein laboratory (WL) nutrient agar, and supplemented with chloramphenicol $(0.5 \mathrm{~g} / \mathrm{L})$ and biphenyl $(1 \mathrm{~g} / \mathrm{L})$ to inhibit the growth of bacteria and moulds, respectively; rod, coccus, and acidophilic LAB were pour plated $(1 \mathrm{~mL})$ into de Man Rogosa Sharpe (MRS) agar, with glucose (5 g/L)-M17 (GM17) agar and medium for Leuconostoc oenos (MLO) agar (pH 4.8) (Caspritz and Radler 1983), respectively. All media used for LAB growth were supplemented with cycloeximide $(170 \mathrm{ppm})$ and biphenyl $(1 \mathrm{~g} / \mathrm{L})$ to inhibit the growth of yeasts and moulds, respectively. All media were purchased by Oxoid (Basingstoke, UK) and chemicals by Sigma-Aldrich. Incubation was at $28 \pm 2{ }^{\circ} \mathrm{C}$ for $48-72 \mathrm{~h}$ for all microorganisms except for acidophilic LAB, which were incubated for 5 days. The incubation of LAB was under anaerobic conditions. Analyses were carried out in duplicate.

Isolation and identification of yeasts

Five representative isolates of yeasts per colony morphology detected for each sample were purified onto WL agar, grouped on the basis of cell morphology, and subjected to genetic characterisation. 
DNA extraction was performed using the InstaGene Matrix kit (Bio-Rad Laboratories, Hercules, CA) according to the manufacturer's instructions.

In order to perform a first differentiation of yeasts, all selected isolates were analysed by restriction fragment length polymorphism (RFLP) of the region spanning the internal transcribed spacers (ITS1 and ITS2) and the 5.8S rRNA gene. The DNA fragments were amplified with the primer pair ITS1/ITS4 (Esteve-Zarzoso et al. 1999) by means of a T1 Thermocycler (Biometra, Göttingen, Germany), and subsequently the amplicons were digested with the endonucleases CfoI, HaeIII, and HinfI (MBI Fermentas, St. Leon-Rot, Germany) at $37^{\circ} \mathrm{C}$ for $8 \mathrm{~h}$. The isolates presumptively belonging to the genus Hanseniaspora were further digested with the restriction enzyme DdeI (MBI Fermentas) (Esteve-Zarzoso et al. 1999). ITS amplicons as well as their restriction fragments were analysed twice on agarose gel using at first 1.5, and then $3 \%(\mathrm{w} / \mathrm{v})$ agarose in $1 \times \mathrm{TBE}(89 \mathrm{mmol} / \mathrm{L}$ Trisborate, $2 \mathrm{mmol} / \mathrm{L}$ EDTA $\mathrm{pH}$ 8) buffer. Gels were stained with SYBR ${ }^{\circledR}$ safe DNA gel stain (Invitrogen, Milan, Italy), visualised by UV transilluminator, and acquired by Gel Doc 1000 Video Gel Documentation System (BioRad, Richmond, USA). Standard DNA ladders were GeneRuler 100 bp DNA Ladder (MBI Fermentas) and GeneRuler 50 bp DNA Ladder (MBI Fermentas). Five isolates representative of each group were subjected to an additional enzymatic restriction targeting the 26S rRNA gene. After amplification with the primer pair NL1/LR6, the PCR products were digested with the endonucleases Hinfl, MseI, and ApaI (MBI Fermentas) (BaleirasCouto et al. 2005), and visualised as above described. One isolate per group was further processed by sequencing the D1/ D2 region of the 26S rRNA gene and/or the 5.8S-ITS rRNA region to confirm the preliminary identification obtained by RFLP analysis. The D1/D2 region was amplified with primers NL1 and NL4 (O’Donnell 1993). PCR products were visualised as above. DNA sequencing reactions were performed at Primmbiotech S.r.l. (Milan, Italy). The identities of the sequences were determined by BlastN search against the NCBI non-redundant sequence database located at http:// www.ncbi.nlm.nih.gov.

\section{Typing of $S$. cerevisiae isolates}

The isolates identified as $S$. cerevisiae were characterised at the intra-species level through two techniques: inter-delta analysis with primers delta12 and delta 21 (Legras and Karst 2003) and microsatellite, multiplex PCR based on the analysis of polymorphic microsatellite loci named SC8132X, YOR267C, and SCPTSY7 (Vaudano and Garcia-Moruno 2008). The PCR products were analysed on agarose gel $2 \%$ $(\mathrm{w} / \mathrm{v})$ in $1 \times \mathrm{TBE}$ buffer and visualised as reported above. To exclude the contamination by the commercial $S$. cerevisiae cultures commonly used in the wine making area of western
Sicily, the strains Zymaflore VL2 (Laffort, Bordeaux, France), Premium Blanc-12 V (Vason, Verona, Italy), and Uvaferm CS2 (Lallemand, Blagnac, France) were analysed as described above.

Isolation and grouping of LAB

After growth, colonies of various shapes (at least five with identical morphology) of Gram-positive (Gregersen $\mathrm{KOH}$ method) and catalase-negative (determined in the presence of $\mathrm{H}_{2} \mathrm{O}_{2} 5 \%$, v/v) bacteria were randomly picked from count plates as presumed LAB, and transferred to the corresponding broth media. The isolates were purified by successive subculturing steps and stored in glycerol at $-80{ }^{\circ} \mathrm{C}$ until further experimentations.

Rod and coccus-shaped LAB cultures were first grouped on the basis of cell disposition, growth at 15 and $45^{\circ} \mathrm{C}$, and $\mathrm{CO}_{2}$ production from glucose. The last test was carried out in the optimal growth media (MRS for rod LAB and M17 for coccus LAB) containing all components except citrate. M17 contained glucose in place of lactose. The assay consisted of $\mathrm{LAB}$ inoculation into test tubes sealed with $\mathrm{H}_{2} \mathrm{O}$ agar $(2 \%$, $\mathrm{w} / \mathrm{v})$. The strains negative to the assay were inoculated into test tubes containing the optimal growth media prepared with a mixture of pentose carbohydrates as reported by Settanni et al (2012b). Coccus isolates were further sub-grouped on the basis of their growth at $\mathrm{pH} 9.2$ and in the presence of $6.5 \%$ $\mathrm{NaCl}$.

Genotypic investigation of LAB at the strain and species levels

DNA extraction was performed as reported above. Strain differentiation was performed by random amplification of polymorphic DNA-PCR (RAPD-PCR) analysis, as reported by Settanni et al (2012b). Two representative cultures for each cluster were identified by $16 \mathrm{~S}$ rRNA gene sequencing, as described by Weisburg et al (1991).

\section{Chemical analyses}

\section{Conventional parameters}

The composition of the wines was determined by means of a Winescan (FOSS) calibrated following EEC 2676 standard procedure (EEC 1990) for $\mathrm{pH}$, total titratable acidity (TTA), volatile acidity (VA), reducing sugars, ethanol, malic acid, lactic acid, citric acid, tartaric acid, promptly assimilable nitrogen (PAN), glycerol, and dry extract. Free and combined $\mathrm{SO}_{2}$ were measured with the OIV method, while the end point was revealed by potentiometry, as reported by Huerta DiazRegagnon (1996). 


\section{Phenolic compounds}

Hydroxycinnamoyl tartaric acids (HCTA) were tested by high-performance liquid chromatography (HPLC) (Di Stefano and Cravero 1992; Corona et al. 2010). The standard employed was chlorogenic acid and the concentration of HCTA was expressed as chlorogenic acid equivalents. By processing these data (hypothetical identity of $\varepsilon$ for chlorogenic and caftaric acids at $220 \mathrm{~nm}$ ) and the data from the coefficients determined by injecting free hydroxycinnamic acids and chlorogenic acid, the concentrations of caftaric, coutaric and fertaric acid were estimated. 2-S-glutathionyl caftaric acid was evaluated in terms of caftaric acid equivalents. The analysis of fixed acids was performed by HPLC on an Agilent series 2100 instrument (Milan, Italy) equipped with a C18 column (EconosphereTM C18, $5 \mu \mathrm{m}, 250 \times 4.6 \mathrm{~mm}$ i.d., Lokeren, Belgium, part $n^{\circ} 70066$ ), volume injected $20 \mu \mathrm{L}$, flow rate $0.6 \mathrm{~mL} / \mathrm{min}$., detection at $210 \mathrm{~nm}$. Prior to injection, a $0.5 \mathrm{~mL}$ of sample was stripped of its phenolics by passing it through a 400-mg C18 Sep Pack cartridge (Sep Pak, Waters, Milan, Italy, part $\mathrm{n}^{\circ}$ WAT036810), activated with $2 \mathrm{~mL}$ of methanol, followed by $3 \mathrm{~mL}$ of $\mathrm{H}_{3} \mathrm{PO}_{4} 10^{-3} \mathrm{M}$ and elution with $\mathrm{H}_{3} \mathrm{PO}_{4} 10^{-3} \mathrm{M}$ until a volume of $10 \mathrm{~mL}$ was reached.

\section{Volatile organic compounds}

Free volatiles were determined according to the method outlined by Corona et al (2010). In brief, $25 \mathrm{~mL}$ of wine, charged with 1-Heptanol as an internal standard $(0.25 \mathrm{~mL}$ of $40 \mathrm{mg} / \mathrm{L}$ hydroalcoholic solution) and diluted to $75 \mathrm{~mL}$ with distilled $\mathrm{H}_{2} \mathrm{O}$, were passed through a 1 -g $\mathrm{C}_{18}$ cartridge (Isolute, SPE Columns, Uppsala, Sweden, part n 221-0100C) previously activated with $3 \mathrm{~mL}$ of methanol followed by $4 \mathrm{~mL}$ of distilled $\mathrm{H}_{2} \mathrm{O}$. After washing with $30 \mathrm{~mL}$ of distilled $\mathrm{H}_{2} \mathrm{O}$, volatiles were recovered by elution with $12 \mathrm{~mL}$ dichloromethane, dehydrated and evaporated to $0.5 \mathrm{~mL}$ prior to injection into the gas chromatograph (GC) (PerkinElmer Autosystem XL, Milan, Italy) and GC-mass spectrometer (MS) (Agilent 6890 Series GC system, Agilent 5973 Net Work Mass Selective Detector, Milan, Italy), both equipped with a DB-WAX column (Agilent Technologies, $30 \mathrm{~m}$, $0.250 \mathrm{~mm}$ i.d., film thickness $0.25 \mu \mathrm{m}$, part $\mathrm{n}^{\circ} 122-7032$ ). Oven temperatures were: $40^{\circ} \mathrm{C}$ for $2 \mathrm{~min}$ (during splitless injection), from 40 to $60^{\circ} \mathrm{C}, 40^{\circ} \mathrm{C} / \mathrm{min}, 60^{\circ} \mathrm{C}$ for $2 \mathrm{~min}$, from 60 to $190{ }^{\circ} \mathrm{C}, 2{ }^{\circ} \mathrm{C} / \mathrm{min}$, from 190 to $230,5^{\circ} \mathrm{C} / \mathrm{min}, 230^{\circ} \mathrm{C}$ for $15 \mathrm{~min}$; injector $250{ }^{\circ} \mathrm{C}$, Fid $250{ }^{\circ} \mathrm{C}$, transfer line $230{ }^{\circ} \mathrm{C}$, carrier helium $1 \mathrm{~mL} / \mathrm{min}$; EM. $70 \mathrm{eV}$. The identification of volatiles was carried out by injection of commercial standards or others prepared in our laboratory (ethyl esters of 2hydroxyglutaric acid) (Di Stefano 1983). Superior alcohols were determined on distilled wine through gaschromatographic analyses with FID detector (GC
PerkinElmer Autosystem XL) (Di Stefano 1980). All solvents and reagents were purchased from WWR International (Milan, Italy). Chemical and physical determinations were performed in triplicate.

\section{Sensory analysis}

A descriptive method (UNI 10957 2003) was used to define the sensory profile of the experimental base wines in comparison to two commercial Grillo base wines for Marsala production produced under conventional regimes. A descriptive panel of ten judges was employed. The judges were trained in some preliminary sessions, using different samples of commercial Marsala base wines obtained by the Grillo cultivar in order to develop a common vocabulary for the description of the sensory attributes of wine samples and to familiarise themselves with scales and procedures. Each attribute term was extensively described and explained to avoid any doubt about the relevant meaning. On the basis of the frequency of citation $(>60 \%), 15$ descriptors were selected to be inserted in the card: colour intensity, odour intensity, odour complexity, off-odour, citrus fruits, fresh fruits, mature fruits, flowers, aromatic herbs (odour), sweet, acidity, bitter, salt (taste), hot (tactile in mouth) and off-flavour (taste). "Terroir" expression was also evaluated.

The wine samples were randomly evaluated by assigning a score between 1 (absence of the sensation) and 9 (extremely intense) in individual booths under incandescent white lighting. The analysis was performed in triplicate. The resulting scores were averaged and compared. An analysis of variance (ANOVA) test (STATISTICA software, StatSoft Inc., Tulsa, OK, USA) was applied to find significant differences among attributes of the wines.

\section{Results}

Microbiological analysis

The evolution of the microbial populations during wine production is reported in Table 1. TY count of the grapes was 4.70 $\log _{10} \mathrm{CFU} / \mathrm{g}$ and remained constant after grape pressing. During AF, TY increased and the highest concentration (7.79 $\log _{10} \mathrm{CFU} / \mathrm{mL}$ ) was registered at the second day of maceration. The level of the yeast community was constant at approximately $7 \log _{10}(\mathrm{CFU} / \mathrm{mL})$ until the first step of aging (clarification 1), and after that, decreased until it reached the lowest value ( $4.40 \log _{10} \mathrm{CFU} / \mathrm{mL}$ ) at the end of aging. Yeasts were no more detectable in wine after 39 days from the beginning of aging.

LAB counts were estimated on three different media as reported in Table 1. The LAB concentration on the grape berries registered onto MRS (2.29 $\left.\log _{10} \mathrm{CFU} / \mathrm{mL}\right)$ was almost 
Table 1 Microbial loads ${ }^{\mathrm{a}}$ of samples collected during natural wine making processes of Marsala base wine

${ }^{\mathrm{a}} \log _{10} \mathrm{CFU} / \mathrm{g}$ for grape berries; $\log _{10} \mathrm{CFU} / \mathrm{mL}$ for must and wine samples

- Under the detection limit

\begin{tabular}{|c|c|c|c|c|}
\hline \multirow[t]{2}{*}{ Steps of wine making } & \multicolumn{4}{|l|}{ Media } \\
\hline & WL & MRS & GM17 & MLO \\
\hline Grapes & $4.70 \pm 0.00$ & $2.29 \pm 0.12$ & $2.22 \pm 0.15$ & - \\
\hline Must & $4.85 \pm 0.00$ & $3.91 \pm 0.37$ & $3.55 \pm 0.27$ & $3.29 \pm 0.02$ \\
\hline \multicolumn{5}{|l|}{ Fermentation: } \\
\hline Day 1 - maceration & $7.34 \pm 0.02$ & $5.87 \pm 0-12$ & $4.41 \pm 0.0 .21$ & $4.39 \pm 0.04$ \\
\hline Day 2 - maceration & $7.79 \pm 0.21$ & $6.15 \pm 0.04$ & $5.11 \pm 0.02$ & $5.16 \pm 0.05$ \\
\hline Day 3 - racking & $7.53 \pm 0.16$ & $3.97 \pm 0.14$ & $3.63 \pm 0.46$ & $2.42 \pm 0.60$ \\
\hline Day 5 & $7.46 \pm 0.40$ & $4.24 \pm 0.28$ & $3.18 \pm 0.14$ & $2.77 \pm 0.10$ \\
\hline Day 7 & $7.75 \pm 0.06$ & $5.15 \pm 0.02$ & $4.14 \pm 0.01$ & $4.10 \pm 0.04$ \\
\hline Day 8 & $7.47 \pm 0.46$ & $4.30 \pm 0.02$ & $2.35 \pm 0.23$ & $4.50 \pm 0.65$ \\
\hline Day 9 & $7.10 \pm 0.21$ & $4.36 \pm 0.11$ & $2.29 \pm 0.15$ & $4.31 \pm 0.13$ \\
\hline \multicolumn{5}{|l|}{ Aging: } \\
\hline Day 3-clarification 1 & $7.35 \pm 0.04$ & $4.39 \pm 0.55$ & $1.74 \pm 0.87$ & $4.15 \pm 0.21$ \\
\hline Day 6-clarification 2 & $6.79 \pm 0.15$ & $2.30 \pm 0.14$ & $1.65 \pm 0.95$ & $2.15 \pm 0.88$ \\
\hline Day 9-transfer & $6.75 \pm 0.02$ & $1.78 \pm 0.02$ & - & $1.45 \pm 0.52$ \\
\hline Day 13 & $4.40 \pm 0.05$ & $0.50 \pm 0.71$ & - & $1.02 \pm 0.70$ \\
\hline \multicolumn{5}{|l|}{ Base wine } \\
\hline Stemmer-crusher & $2.80 \pm 0.11$ & - & - & - \\
\hline Hydraulic press & $1.85 \pm 0.09$ & - & - & - \\
\hline Steel tank & $1.97 \pm 0.11$ & - & - & - \\
\hline
\end{tabular}

superimposable to that displayed by GM17 (2.22 $\log _{10}$ $\mathrm{CFU} / \mathrm{mL}$ ), while no growth occurred on the MLO medium. After grape crushing, the LAB population increased by about one $\log _{10}$ cycle for all media. After two days of $\mathrm{AF}, \mathrm{LAB}$ reached the highest concentrations $\left(6 \log _{10} \mathrm{CFU} /\right.$ $\mathrm{mL}$ onto MRS and about $5 \log _{10} \mathrm{CFU} / \mathrm{ml}$ onto GM17 and MLO). A decrease in concentration was registered after racking. During aging, the greatest reduction of the LAB population was observed onto GM17, and they were not detectable at the end of the process.

Cellar equipment surfaces showed a yeast presence at low concentrations (around $2 \log _{10} \mathrm{CFU} / \mathrm{mL}$ ) and the highest value was detected on stemmer-crusher surfaces $\left(2.80 \log _{10}\right.$ $\mathrm{CFU} / \mathrm{mL}$ ). LAB were not detected.

Identification and distribution of yeasts

A total of 1,077 colonies from the WL agar were isolated, purified to homogeneity on the same medium and distinguished on the basis of colony appearance. At least five cultures from each sample were selected and 529 isolates were subjected to the molecular identification. After restriction analysis of the 5.8S-ITS region and $26 \mathrm{~S}$ rRNA gene, the isolates were clustered into five groups (Table 2). Four groups were identified by comparison of the restriction bands with those available in the literature (Nisiotou and Nychas 2007; Tofalo et al. 2009; Esteve-Zarzoso et al. 1999) and were allotted in the following species: Hanseniaspora guilliermondii (group I), Metschnikowia pulcherrima (group III), Pichia guilliermondii (group IV), and S. cerevisiae (group V). Group II could not be identified at the species level by RFLP analysis, as the sequencing of the D1/D2 domain of the 26S rRNA gene was necessary. This strategy identified the isolates of group II as Hanseniaspora uvarum. The same tool was also applied to confirm the previous species.

The distribution of yeast species and the highest concentrations estimated for each sample are reported in Table 2. $S$. cerevisiae and $P$. guilliermondii were isolated from all steps of wine making and both resulted in high levels during AF as well as aging. The Hanseniaspora genus was detected from the grape harvest to the AF period, while $M$. pulcherrima species was detected on the grape berries. The surface of the cellar equipment hosted only the species $H$. guilliermondii and M. pulcherrima.

\section{Differentiation and distribution of $S$. cerevisiae strains}

The 207 isolates belonging to the $S$. cerevisiae species were further genetically investigated. The inter-delta analysis was able to separate the isolates into 20 groups (Fig. 1), while the microsatellite multiplex PCR recognized 16 different groups (results not shown), showing a lower discriminatory power than the first technique. The distribution of the different strains of $S$. cerevisiae during wine making is reported in Fig. 1. A few strains were isolated before AF: one (GRBRL5) from grapes and two (GRBRL12 and GRBRL17) from must. Only 


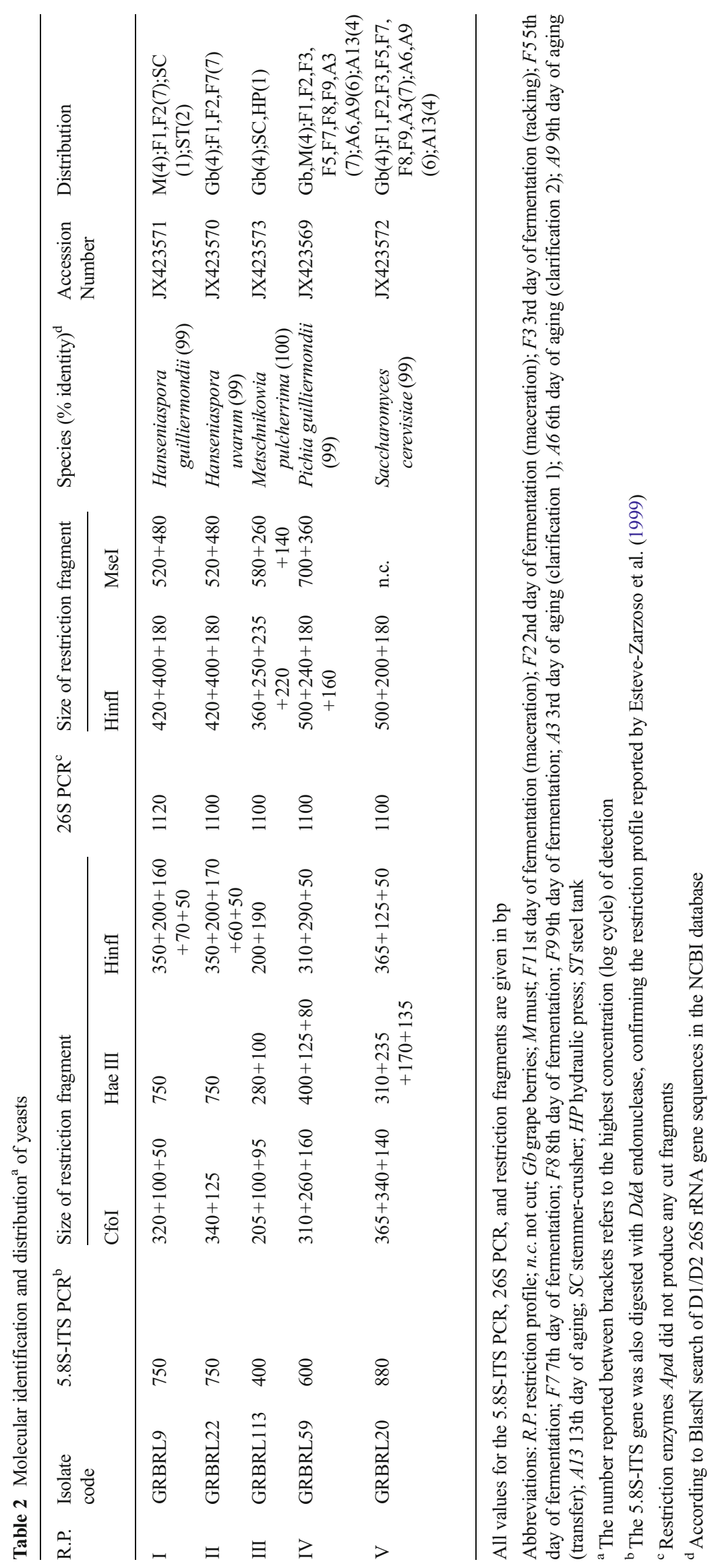


the last two strains were also found during $\mathrm{AF}$, specifically at the maceration step. A high variety of strains (16) at dominating levels was found during the AF, in particular at day 5 . During aging, a total of four strains were detected and only one (GRBRL32) came from the AF phase.

All strains isolated in our study showed genotypic profiles different from those presented by commercial strains used as controls (data not shown).

Isolation, identification, and distribution of $\mathrm{LAB}$

A total of 1,177 bacterial cultures were picked up from MRS, GM17, and MLO agar plates at the highest dilutions of samples, and propagated in the broth media corresponding to those used for counts, applying the same incubation conditions. The cultures were purified as reported above, and the microscopic inspection allowed their separation into 914 rods and 263 cocci. After Gram characterization and catalase testing, 721 rods and 231 cocci were considered presumptive LAB cultures, being Gram-positive and catalase-negative.

The phenotypic characterisation allowed for the separation of the $926 \mathrm{LAB}$ cultures into five groups (Table 3), two for rods and three for cocci. $\mathrm{CO}_{2}$ production from glucose was scored negative for the isolates of group $\mathrm{E}$, which were tested for growth in presence of pentose sugars, evidence of their facultative heterofermentative metabolism.

About $30 \%$ of the isolates of each phenotypic group ( $n=$ 274) were subjected to RAPD analysis using primer M13 (results not shown). The isolates analysed were divided into eight main clusters for the five phenotypic groups: two clusters for group $\mathrm{A}$, two for group $\mathrm{B}$, one for group $\mathrm{C}$ and $\mathrm{D}$, and two clusters for group E (Table 4). One strain for each RAPD profile was identified at the species level by 16S rRNA gene sequencing. The BLAST search shared a percentage of identity with sequences available in the NCBI database of at least $97 \%$, which is considered the minimum level of similarity for $16 \mathrm{~S}$ rRNA genes of two strains belonging to the same species (Stackebrandt and Goebel 1994). Enterococcus faecium, Lactobacillus hilgardii, Lactobacillus plantarum, Leuconostoc mesenteroides, and Streptococcus macedonicus were found.

The distribution of LAB and their concentrations estimated for each sample are shown in Table 4. Grapes showed the highest LAB diversity. After grape harvest, Lactobacillus hilgardii and E. faecium were no longer detected. On the other hand, Lactobacillus plantarum was the species most encountered at the highest concentration during the entire AF period. Leuconostoc mesenteroides was isolated at the highest dilutions of samples until the second day of AF. During aging, Lactobacillus plantarum was the only LAB species detected, but at lower concentrations than AF. Streptococcus macedonicus was found only at the sixth day of aging (clarification 2).
Chemical analyses

\section{Conventional parameters}

The wine making process was chemically monitored by the analysis of conventional parameters, and the results are reported in Table 5. Values of $\mathrm{pH}$, TTA, tartaric acid, total $\mathrm{SO}_{2}$, free $\mathrm{SO}_{2}$ and combined $\mathrm{SO}_{2}$ were in the range of those reported for commercial wines. The concentrations of reducing sugars rapidly decreased during the first days of AF; after racking, their concentrations decreased more slowly. These sugars were no more detectable at the end of the process. On the contrary, ethanol and glycerol showed a rapid increase from the first day of AF $(0.53 \% \mathrm{v} / \mathrm{v}$ of ethanol, $0.77 \mathrm{~g} / \mathrm{L}$ of glycerol) to racking $(4.27 \% \mathrm{v} / \mathrm{v}$ of ethanol, $4.97 \mathrm{~g} / \mathrm{L}$ of glycerol). At the end of wine making, ethanol reached $14.72 \%(\mathrm{v} / \mathrm{v})$ and glycerol $8.29 \mathrm{~g} / \mathrm{L}$. PAN concentration varied greatly during the first days of AF and could not be detected 8 days after the beginning of the process. VA content remained almost constant during the maceration. After racking, its concentration started to increase and its maximum concentration $(0.5 \mathrm{~g} / \mathrm{L})$ was estimated at the fifth day of fermentation; from the seventh day of fermentation, the VA concentration decreased and remained almost constant (comprised between 0.2 and $0.3 \mathrm{~g} / \mathrm{L}$ acetic acid) until the end of monitoring. The content of citric and malic acids were almost stable during the experimental process, their highest values estimated at the second $(0.28 \mathrm{~g} / \mathrm{L})$ and at the first day of fermentation $(0.44 \mathrm{~g} / \mathrm{L})$, respectively. Lactic acid concentration showed an irregular behaviour during fermentation, while its concentration was almost constant during aging.

\section{Phenolic compounds}

The results of HCTA analysis are graphically reported in Fig. 2. Among these compounds, the trans-caffeoyl tartaric acid rapidly increased; its highest concentration (approximately $95 \mathrm{mg} / \mathrm{L}$ ) was registered at the seventh day of AF (F7), and after that its value was almost constant until the end of the process. A different trend was observed for 2-S-glutationiltrans-caffeoyl tartaric acid, known as a grape reaction product (GPR) (Salgues et al. 1986), which showed a rapid decrease during the maceration period (from $\mathrm{M}$ to $\mathrm{F} 2$ step) until $19.05 \mathrm{mg} / \mathrm{L}$ (F2) that remained constant. On the other hand, trans-p-cumaril tartaric acid showed a low concentration $(8.36 \mathrm{mg} / \mathrm{L})$ after pressing and increased to a value superimposable to GPR. Other chemicals such as cis-pcumaril tartaric, caffeoyl tartaric, caffeic, and trans-feruil tartaric acids did not show significant changes in concentration during the entire vinification process. The lowest HCTA value during wine making was registered for trans-feruil tartaric acid. 


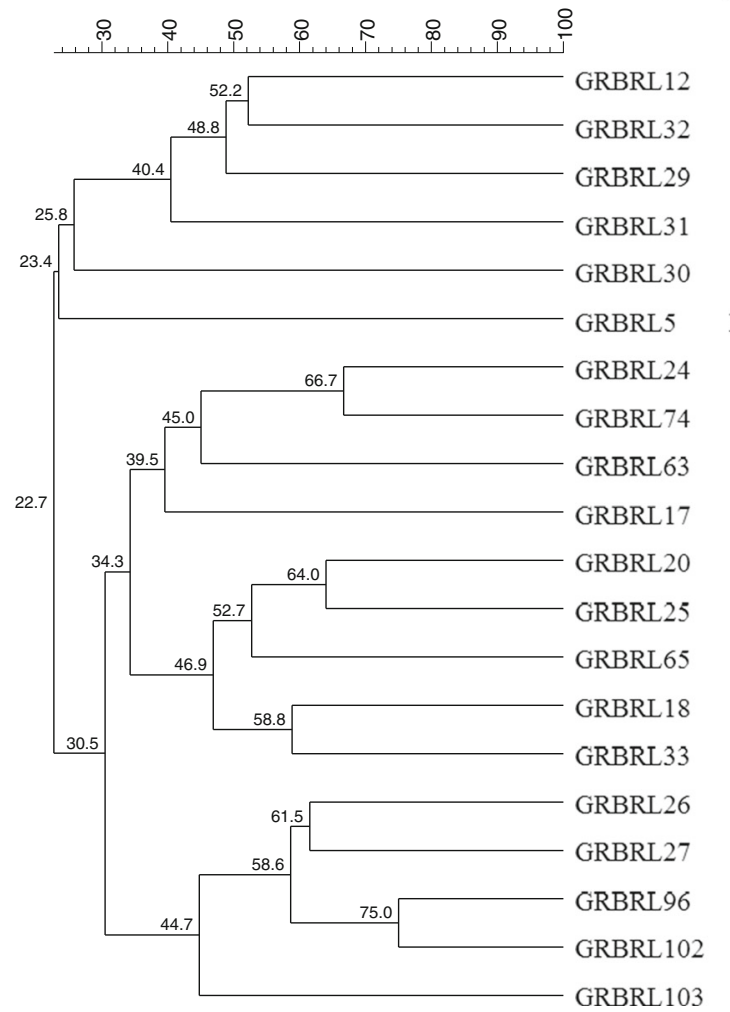

Fig. 1 Dendogram of inter-delta profiles of S. cerevisiae strains and their distribution during vinification. Abbreviations: $M$ must; $F 11$ st day of fermentation (maceration); $F 2$ 2nd day of fermentation (maceration); $F 3$ 3 rd day of fermentation (racking); $F 55$ th day of fermentation; $F 77$ th day of fermentation; $F 88$ th day of fermentation; $F 99$ th day of fermentation; A3 3rd day of aging (clarification 1); A6 6th day of aging (clarification 2);

\section{Concentration of VOCs and sensory analysis}

VOCs (Table 6) were composed of alcohols, esters, acetate esters, and acids. Alcohols were mainly represented by higher

Table 3 Phenotypic grouping of LAB

\begin{tabular}{|c|c|c|c|c|c|}
\hline \multirow[t]{2}{*}{ Characters } & \multicolumn{5}{|l|}{ Clusters } \\
\hline & $\begin{array}{l}\text { A } \\
(n=187)\end{array}$ & $\begin{array}{l}\mathrm{B} \\
(n=35)\end{array}$ & $\begin{array}{l}\mathrm{C} \\
(n=9)\end{array}$ & $\begin{array}{l}\mathrm{D} \\
(n=4)\end{array}$ & $\begin{array}{l}\mathrm{E} \\
(n=717)\end{array}$ \\
\hline Morphology & Coccus & Coccus & Coccus & Rod & Rod \\
\hline \multicolumn{6}{|l|}{ Growth: } \\
\hline $15^{\circ} \mathrm{C}$ & + & + & - & + & + \\
\hline $45^{\circ} \mathrm{C}$ & - & + & + & - & - \\
\hline pH 9.6 & - & + & - & n.d. & n.d. \\
\hline $6.5 \% \mathrm{NaCl}$ & + & + & - & n.d. & n.d. \\
\hline $\mathrm{CO}_{2}$ from glucose & + & - & - & + & - \\
\hline $\begin{array}{l}\text { Growth in the } \\
\text { presence of pentose } \\
\text { carbohydrates }\end{array}$ & n.d. & n.d. & n.d. & n.d. & + \\
\hline
\end{tabular}

n.d. not determined
GB M F1 F2 F3 F5 $\quad$ F7 F8 F9 A3 A6 A9 A13

$$
\begin{aligned}
& \begin{array}{llll}
X & X & X
\end{array} \\
& \text { X } \mathrm{X} \\
& \mathrm{X} \\
& \mathrm{X} \\
& \text { X } \\
& \mathrm{X} \\
& \mathrm{X} \\
& \mathrm{X} \quad \mathrm{X} \\
& \text { X } \quad \mathrm{X} \\
& \mathrm{X} \\
& \mathrm{X} \\
& \text { X } \\
& \mathrm{X} \\
& \mathrm{X} \\
& \text { X X }
\end{aligned}
$$

\section{$\mathrm{X}$}

A9 9th day of aging (transfer); $A 13$ 13th day of aging; $B$ base wine. Symbols: small diamond caffeil tartaric acid; square trans-caffeoyl tartaric acid; triagle 2-S-glutationil-trans-caffeoyl tartaric acid; big circle cis-p-cumaril tartaric acid; big diamond trans-p-cumaril tartaric acid; small circle trans-feruil tartaric acid; horizontal bar, caffeic acid

alcohols that showed an increasing trend until the end of the process. Among this group, the highest concentrations were reached by isoamylic alcohol and isobutanol. The levels of esters and acetate esters increased during the alcoholic fermentation. In particular, diethyl succinate, ethyl octanoate, 4-OH-butyrate eth$y l$, hexanoate, and ethyl decanoate showed the highest concentrations among esters, while ethyl acetate represented more than $97 \%$ of total acetate esters. Except decanoic acid, whose content was almost constant, all acids reached high levels of concentration showing an increasing trend.

The final base wine was sensory analysed, and the results are represented in Fig. 3. The different samples showed significant $(p<0.05)$ differences only for odour complexity, citrus fruits, aromatic herbs and "terroir" expression. The higher values were displayed by the experimental wine obtained under the natural wine making process.

\section{Discussion}

The spontaneous fermentation of wine is characterised by a high microbial diversity. Although the oenological operations 


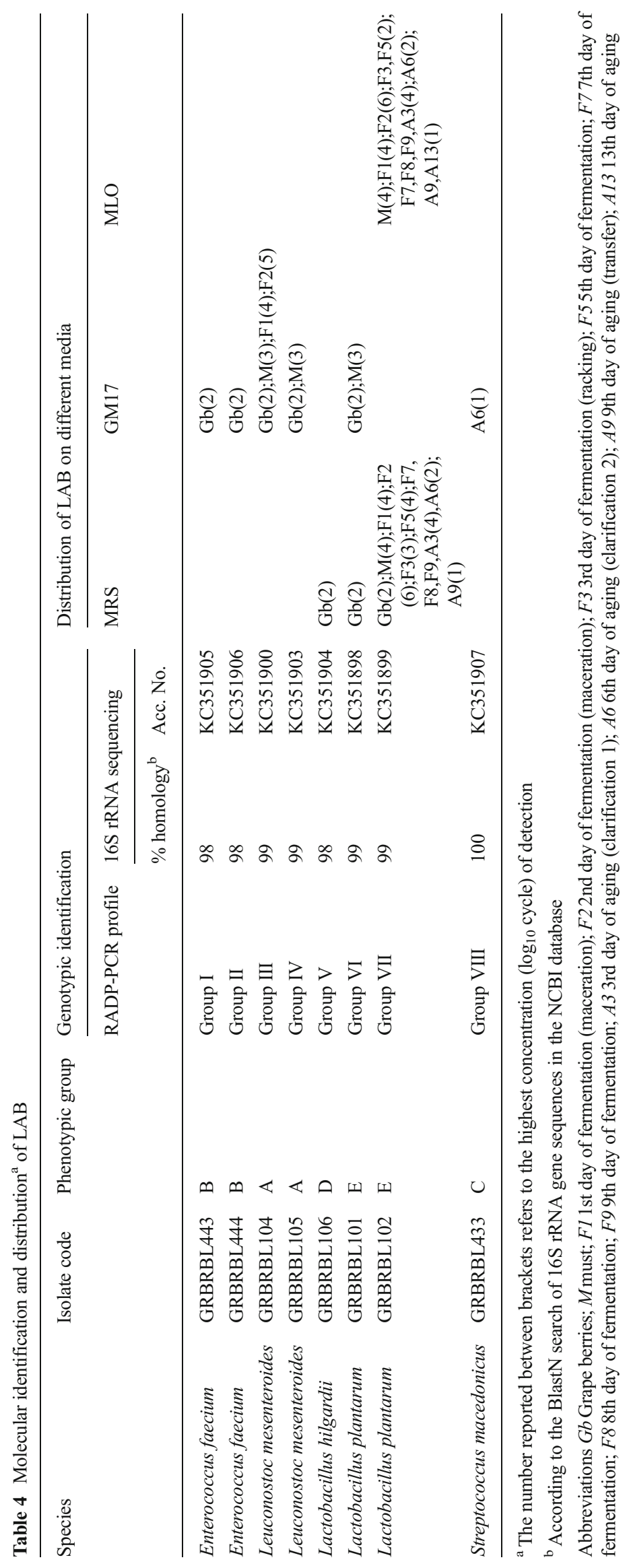




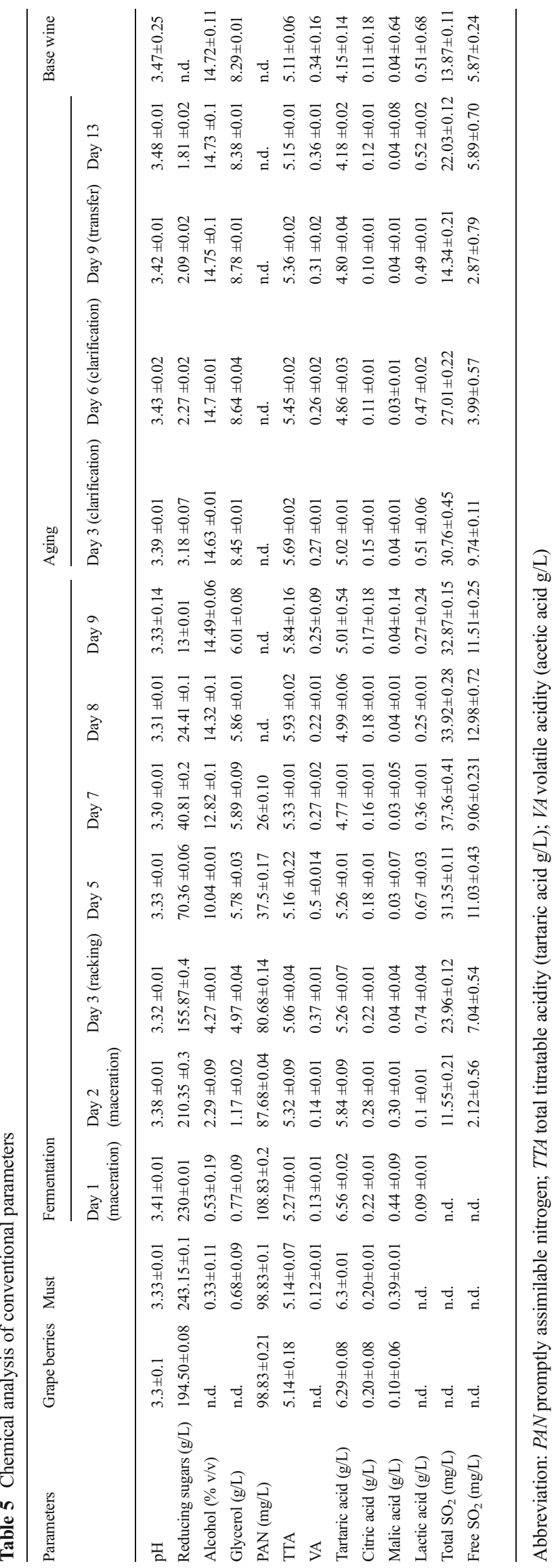

(mainly, the addition of starters and adjuvants) commonly applied during conventional wine making, to a certain extent, ensure the success of fermentation by inhibiting the undesired microorganisms, reducing the number of indigenous species/strains involved in the typicality of the final products.

On the basis of these considerations, the present work was aimed at studying, in terms of microbial, chemical, and sensorial traits, "natural wine making" carried out on a large scale for the production of a base wine to be transformed into CDO Marsala. Grapes of Grillo cultivar were harvested and subjected to a spontaneous AF without oenological additives. The process was monitored from the grape harvest until the end of the production process.

Although the experimental vinification was performed following the criteria of "natural wine" with no yeast starters inoculated, the microbial counts showed a rapid increase of yeast populations (until seven orders of magnitude) during the entire AF phase. Despite data reported in the literature, LAB concentrations also reached their highest values at the beginning of AF.

Generally, LAB growth occurs at the end of AF when yeast activities greatly decrease and their cells undergo lysis due to the wine stressing conditions such as high ethanol content, nutrient limitations, and low pH (Vincenzini et al. 2005). LAB increase is commonly favoured by the absence of exogenous suplhites, but it is also greatly inhibited by yeasts during AF when this process is carried out without the addition of suplhites (Granchi et al. 2005).

The growth of yeasts and LAB during spontaneous fermentation represents a complex phenomenon affected by several oenological factors. Since our study was not aimed at studying the diversity of yeasts and LAB during one vintage and in one cellar, no correlations could be defined among our results and among the specific technological conditions of the experimental vinification. On the other hand, our process was carried out in duplicate and following wine production at industrial level, thus the results reported provide additional information on yeast ecology during a natural vinification of Marsala base wine.

The analysis of yeast species evolutions during winemaking is of paramount importance to interpreting the data registered during an experimental process. For this reason, yeasts were isolated and identified at the species level. Although $S$. cerevisiae is not commonly reported to be the main species during the first phase of spontaneous fermentation (Vincenzini et al. 2005), in our study this species was mainly isolated from the first day of AF. Generally, this condition is realised thanks to the inoculation of selected strains of $S$. cerevisiae, as well as the addition of sulphites into the just-pressed must that ensure a rapid growth of the starter over the non-Saccharomyces yeasts (Vincenzini et al. 2005). 


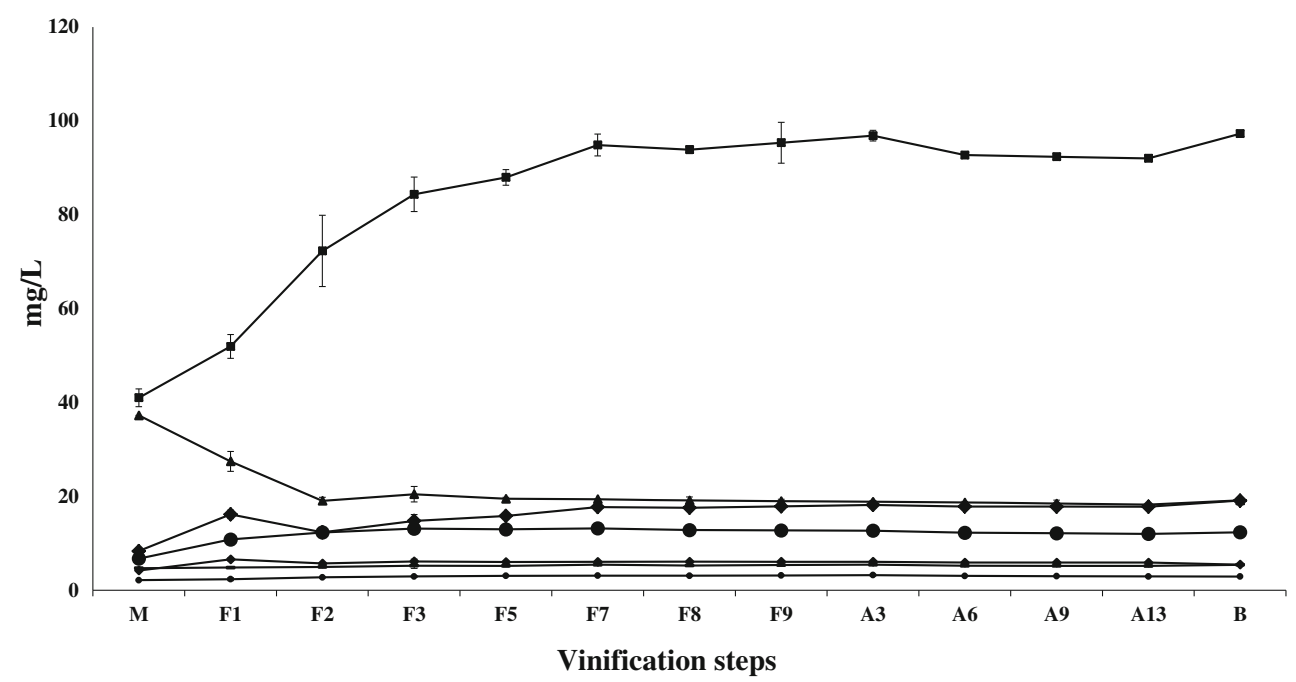

Fig. 2 Distribution of hydroxycinnamoyl tartaric acids during wine making. Abbreviations: Mmust; F1 1st day of fermentation (maceration); $F 2$ 2nd day of fermentation (maceration); F3 3rd day of fermentation (racking); F5 5th day of fermentation; F7 7th day of fermentation; $F 88$ th day of fermentation; F9 9th day of fermentation; $A 3$ 3rd day of aging (clarification 1); A66th day of aging (clarification 2); A99th day of aging

Even though it is not possible to make a clear correlation based on our data between the technological condition of natural fermentation and the $S$. cerevisiae distribution during wine making, the first days of a spontaneous AF carried out in the absence of exogenous sulphites are generally characterised by a rapid increase of non-Saccharomyces yeasts, and only at the end of the fermentation process are the yeasts showing alcohol tolerance detected (Wang and Liu 2013).

In our study, among non-Saccharomyces yeasts, only $P$. guilliermondii was isolated and counted at the same concentration of $S$. cerevisiae during both fermentation and aging. This species is commonly found on grapes and during the first steps of AF (Ciolfi et al. 2012), but at low concentrations. However, P. guilliermondii does not represent a species commonly used as starter or co-starter for wine fermentation, even though recent studies (Barata et al. 2006) reported this species to be responsible for the fermentation process and to affect the final quality.

The classic microbiological analysis, as well as the culturebased molecular approach carried out in our study could understate the microbial diversity of natural wine productions. Thus, further investigations based also on culture-independent molecular analysis (Urso et al. 2008; Zott et al. 2010; Tofalo et al. 2012) may provide more information on yeast biodiversity and dynamics during the natural wine making process.

Saccharomyces cerevisiae isolated during the experimental wine making were further investigated at the strain level. As expected from a spontaneous fermentation, different $S$. cerevisiae strains were detected at the various steps of production. The presence of a multi-strain $S$. cerevisiae population during $\mathrm{AF}$ could positively affect the organoleptic (transfer); $A 13$ 13th day of aging; $B$ base wine. Symbols: small diamond caffeoyl tartaric acid; square trans-caffeoyl tartaric acid; triagle 2-Sglutationil-trans-caffeoyl tartaric acid; big circle cis-p-cumaril tartaric acid; big diamond trans-p-cumaril tartaric acid; small circle trans-feruil tartaric acid; horizontal bar caffeic acid

complexity of the final product due to different metabolic activities (Fleet 2003). The number of strains $(n=16)$ isolated at the highest level during AF was considerable and higher than those commonly reported in the literature (Wang and Liu 2013; González et al. 2007). Interestingly, only two S. cerevisiae strains (GRBRL12 and GRBRL17) isolated from grapes were detected at the highest level during AF. All other strains were first detected during $\mathrm{AF}$ and/or the aging of the wine.

Even though several studies (Le Jeune et al. 2006; Guzzon et al. 2011) showed that the cellar represents an interesting source of indigenous fermenting strains that could play a defining role during fermentation, in our work only the species $H$. guilliermondii and $M$. pulcherrima were detected on the cellar equipment surfaces. Further investigations to evaluate the yeast populations present at low concentrations, on grape surfaces, and inside the grape must could better explain the presence of several indigenous $S$. cerevisiae detected during the experimental process.

The wine making process under investigation was also monitored in terms of LAB species diversity. The highest $\mathrm{LAB}$ diversity was found on grapes and into the just-pressed must, from which E. faecium, Lactobacillus hilgardii, and Lactobacillus plantarum (RAPD-PCR profile VI) were isolated. Although these species do not show relevant roles during wine production, several works reported the presence of E. faecium and Lactobacillus hilgardii on grapes and/or into wine (Rodriguez and Manca de Nadra 1995; Garcia-Ruiz et al. 2009). After must pressing, only Lactobacillus plantarum, Leuconostoc mesenteroides, and Streptococcus macedonicus were detected. Lactobacillus plantarum was the species most 
Table 6 Volatile organic compounds

\begin{tabular}{|c|c|c|c|c|}
\hline \multirow[t]{2}{*}{ Compounds } & \multicolumn{3}{|l|}{ Fermentation } & \multirow[t]{2}{*}{ Base wine } \\
\hline & Day 3 (racking) & Day 7 & Day 9 & \\
\hline Higher alcohols (mg/L) & 231.97 & 380.57 & 463.34 & 564.09 \\
\hline n-propanol & $17.59 \pm 0.78$ & $29.99 \pm 1.23$ & $30.79 \pm 1.34$ & $39.58 \pm 1.76$ \\
\hline Isobutanol & $33.70 \pm 2.02$ & $45.69 \pm 2.57$ & $67.18 \pm 3.32$ & $88.87 \pm 4.32$ \\
\hline Isoamyl alcohol & $138.17 \pm 3.45$ & $230.07 \pm 4.54$ & $299.41 \pm 4.32$ & $383.86 \pm 5.01$ \\
\hline Phenyl 2-ethanol & $42.51 \pm 5.02$ & $74.82 \pm 6.45$ & $65.96 \pm 3.32$ & $51.78 \pm 8.31$ \\
\hline Other alcohols $(\mu \mathrm{g} / \mathrm{L})$ & 2075.24 & 2470.39 & 2255.35 & 2309.35 \\
\hline 1-Hexanol & $1930.36 \pm 122.85$ & $2252.87 \pm 143.37$ & $2058.67 \pm 131.01$ & $2111.70 \pm 134.39$ \\
\hline trans-3-Hexenol & $31.79 \pm 2.02$ & $42.08 \pm 2.68$ & $35.96 \pm 2.29$ & $29.13 \pm 1.85$ \\
\hline cis-3-Hexenol & $87.15 \pm 6.16$ & $87.63 \pm 6.20$ & $70.86 \pm 5.01$ & $62.26 \pm 4.40$ \\
\hline 3-Methyl pentan-1-olo & $25.94 \pm 1.47$ & $87.81 \pm 4.97$ & $89.86 \pm 5.08$ & $106.26 \pm 6.01$ \\
\hline Esters $(\mu \mathrm{g} / \mathrm{L})$ & 2999.7 & 4434.04 & 5888.56 & 5944.13 \\
\hline Etyl 3-OH-butanoate & $22.31 \pm 0.95$ & $83.60 \pm 3.55$ & $119.95 \pm 5.09$ & $109.69 \pm 4.65$ \\
\hline Ethyl 4-OH-butyrate & $652.54 \pm 18.46$ & $1560.70 \pm 44.14$ & $2098.05 \pm 59.34$ & $2000.40 \pm 56.58$ \\
\hline Diethyl malate & $18.27 \pm 0.65$ & $47.67 \pm 1.69$ & $71.98 \pm 2.54$ & $102.10 \pm 3.61$ \\
\hline Isoamyl 4-OH-butyrate & $15.29 \pm 0.65$ & $92.59 \pm 3.93$ & $148.53 \pm 6.30$ & $134.59 \pm 5.71$ \\
\hline Ethyl lactate & $145.98 \pm 10.32$ & $357.34 \pm 25.27$ & $404.59 \pm 28.61$ & $511.90 \pm 36.20$ \\
\hline Diethyl succinate & $325.68 \pm 23.03$ & $689.88 \pm 48.78$ & $888.33 \pm 62.81$ & $1511.84 \pm 106.90$ \\
\hline 2-Ethyl hexanoic acid & $7.49 \pm 0.32$ & $22.24 \pm 0.94$ & $23.62 \pm 1.00$ & $53.59 \pm 2.27$ \\
\hline Ethyl hexanoate & $583.28 \pm 33.00$ & $620.79 \pm 35.12$ & $589.71 \pm 33.36$ & $386.79 \pm 21.88$ \\
\hline Ethyl octanoate & $859.96 \pm 48.65$ & $591.25 \pm 33.45$ & $890.94 \pm 50.40$ & $724.81 \pm 41.00$ \\
\hline Ethyl decanoate & $346.46 \pm 19.60$ & $358.77 \pm 20.30$ & $644.69 \pm 36.47$ & $395.68 \pm 22.38$ \\
\hline Ethyl 9-decanoate & $22.44 \pm 1.59$ & $9.21 \pm 0.85$ & $8.17 \pm 0.58$ & $12.74 \pm 0.90$ \\
\hline Acetate esters $(\mu \mathrm{g} / \mathrm{L})$ & 43886.79 & 62494.85 & 80567.85 & 130121.5 \\
\hline Ethyl acetate & $38920.01 \pm 456.87$ & $57540.12 \pm 651.02$ & $76170.24 \pm 792.12$ & $126300.11 \pm 856.29$ \\
\hline Isoamyl acetate & $1227.32 \pm 43.39$ & $1536.58 \pm 54.33$ & $1512.54 \pm 53.48$ & $1800.09 \pm 63.64$ \\
\hline Hexyl acetate & $76.13 \pm 3.77$ & $51.41 \pm 2.54$ & $34.04 \pm 1.69$ & $32.03 \pm 1.59$ \\
\hline Phenyl-2-ethanol acetate & $3663.33 \pm 129.52$ & $3366.74 \pm 119.03$ & $2851.03 \pm 100.80$ & $1989.31 \pm 70.33$ \\
\hline Acids $(\mu \mathrm{g} / \mathrm{L})$ & 4970.84 & 12161.33 & 9480.24 & 14057.92 \\
\hline Butyric acid & $9.22 \pm 0.39$ & $21.41 \pm 0.91$ & $18.07 \pm 0.77$ & $13.95 \pm 0.59$ \\
\hline Isovalerianic acid & $172.49 \pm 7.32$ & $379.07 \pm 16.08$ & $352.98 \pm 14.98$ & $230.99 \pm 9.80$ \\
\hline Hexanoic acid & $1737.96 \pm 61.45$ & $2338.77 \pm 82.69$ & $2120.06 \pm 74.96$ & $1967.80 \pm 69.57$ \\
\hline Octanoic acid & $1872.11 \pm 79.43$ & $5076.39 \pm 215.37$ & $2885.35 \pm 122.42$ & $3514.85 \pm 149.12$ \\
\hline Decanoic acid & $455.53 \pm 16.11$ & $2472.05 \pm 87.40$ & $1796.24 \pm 63.51$ & $1532.53 \pm 54.18$ \\
\hline Monoethyl succinic acid & $723.53 \pm 25.58$ & $1873.64 \pm 66.24$ & $2307.54 \pm 81.58$ & $6797.80 \pm 240.34$ \\
\hline
\end{tabular}

frequently encountered during the entire wine making process. Different studies detected the presence of Lactobacillus plantarum in the wine environment, revealing its tolerance to different wine stressing conditions (Rojo-Bezares et al. 2007). Although further investigations carried out for several vintages and in different cellars are necessary to define the LAB ecology of Marsala base wine, to our knowledge, this is the first work that shows Lactobacillus plantarum at high concentrations during the entire wine making process and concomitantly with the maximum increase of yeasts during AF. The present study showed the presence of $S$. macedonicus in the wine; this bacterium is typically associated with cheese environments (De Vuyst and Tsakalidou 2008).

The natural wine making process is strongly affected by several microbial spoilage issues (Vincenzini et al. 2005). For this reason, the experimental process was also chemically monitored. The values of the conventional parameters of our final wine product were in agreement with those reported for the production regulation of Grillo and Marsala commercial wines (D.P.R. 17 1987).

The $\mathrm{pH}$ values did not significantly increase during the wine making process, and the reducing sugars were rapidly 
Fig. 3 Sensory profiles of Marsala base wines. $M N b w$ natural Grillo base wine; $M C b w-1$ conventional Grillo base wine 1; $M C b w-2$ conventional Grillo base wine $2 .{ }^{*}$ significant differences among attributes of the wines

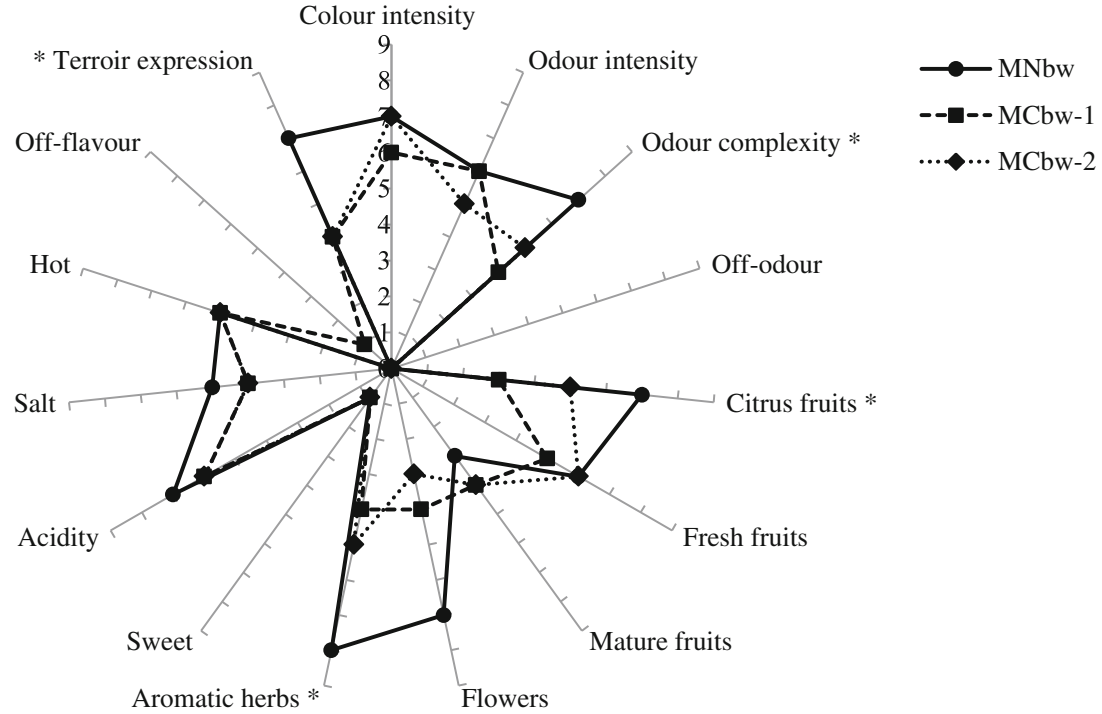

metabolised by yeasts during AF. In fact, more than $97 \%$ of the final content of wine ethanol was already reached at the eighth day of AF due to the consistent increase of yeast concentration, especially the $S$. cerevisiae species.

Marsala is a special wine whose production regulation (D.P.R. 17 1987) requires a final ethanol concentration in the range of $17-18 \%(\mathrm{v} / \mathrm{v})$ when it is for a commercial purpose. Commonly, base wines for Marsala production do not reach the ethanol content required for bottled Marsala wine. For this reason, the base wines are subjected to the addition of ethanol before aging in barrels. Our experimental base wine showed high ethanol content and low $\mathrm{pH}$, the achievement of which are the two main hurdles to the microbial alteration of wine and the preservation of its organoleptic quality (Vincenzini et al. 2005).

Glycerol is relevant for the sensorial quality of wine because it contributes to the roundness sensation of the final product (Nurgel and Pickering 2005). After the second day of $\mathrm{AF}$, chemical analysis revealed a consistent production of this compound probably due to the glycero-pyruvic fermentation carried out by the yeasts (Vincenzini et al. 2005). Organic acids with low molecular weight were also monitored because they are of paramount relevance for the shelf-life and final organoleptic characteristics of wine. During wine making, VA was detected at low concentrations, probably due to the presence of yeast strains producing low concentrations of acetic acid. VA at high concentrations (more than $1 \mathrm{~g} / \mathrm{L}$ ) in wine are responsible for the generation of the off-flavours (Vincenzini et al. 2005) and make the product unmarketable. Wines carried out by spontaneous fermentations are frequently characterised by high VA concentrations due to the proliferation of spoilage yeasts (Wang and Liu 2013). However, the processing of healthy grapes as well as the proper sanitisation of the cellar equipment are two optimal conditions to limit the risk of wine spoilage (Guzzon and Settanni 2009).
Tartaric acid did not greatly vary during the entire process, and its changes were according to those registered during conventional vinifications (Radin et al. 1994). On the other hand, a considerable change of both malic and lactic acid concentrations was detected during wine making. Malolactic fermentation (MLF) registered during the first days of AF was probably due to the growth of Lactobacillus plantarum. Other studies reported Lactobacillus plantarum as a species with a strong malo-lactic activity (Lopez et al. 2008; Rojo-Bezares et al. 2007).

The concentration of lactic acid showed correlations with the microbial activities, increasing during LAB development and decreasing with yeast growth. The analysis of HCTA are of paramount relevance to checking the quality of a white wine produced with maceration. This technological step is responsible for the extraction of several phenolic compounds, such as HCTA, from the skin. A prolonged maceration time could generate an excessive extraction of these compounds that could be oxidized to brown pigments and/or volatile phenols (off-odours) (Ribéreau-Gayon et al. 2003). However, their concentration in the experimental wine did not greatly differ from those reported for conventional wine making (Singleton et al. 1978). Trans-caffeoyl tartaric acid was one of the most abundant HCTAs detected in the Grillo wine. This compound is generally highly concentrated into the skin and pulp of the grape; its extraction from the grape occurs during maceration and could positively improve the body and complexity of wine (Baro et al. 1997; Garcì-Parrilla et al. 1999). GPR, an important precursor for antioxidant molecules, was also detected in the final product.

VOCs are greatly influenced by yeasts and LAB activities (Valentao et al. 2007). In our samples, alcohols as well as esters were found at high concentrations during the wine making, and isoamylic alcohol and isobutanol were the most abundant compounds. They are generally produced in the pre- 
fermentative phase (pressing and maceration) (Oliveira et al. 2003) and might positively affect the organoleptic complexity of wines. As detected in other spontaneously fermented wines, high level of esters, mainly acetate ester, were also observed in our samples. Ethyl acetate was mostly detected; it could be responsible for the fruit as well as the balsamic aroma of wines (Radeka et al. 2012; Francis and Newton 2005). Among VOCs, different acids were found at high concentrations, such as octanoic acid. VOCs can increase a wine's finesse and persistence with wax and honey flavours that are commonly required by specialised wine consumers. In order to exclude the influence of organoleptic alterations that are common in wines produced by natural wine making, the final wine in our study was subjected to sensory evaluation. No off-odours or off-flavours were detected.

In conclusion, during the natural wine making process, the main microbial populations (yeasts and LAB) were able to express metabolic activities, and no negative impacts on wine chemistry and wine microbiology were detected. All conventional chemical parameters of wine were in agreement with those reported for the regulated commercial production of Marsala base wine, and no off-odours or off-flavours were detected.

Taking into account that our study was carried out in one cellar only for 1 year, further investigations on the yeast and $\mathrm{LAB}$ ecology of natural Marsala wines will be performed in other cellars for longer observation periods. Additional works are being prepared to determine the effects of technological conditions on wine quality, with the aim to improve the market sales of Marsala wines in response to the rising demand for natural wines.

Acknowledgment The authors wish to thank students Giuseppe Bennardo and Stefano Daidone (University of Palermo) for their help with the microbiological and chemical analyses. Antonino Barraco, the owner of the winery where the experimentation was carried out, is also thanked.

\section{References}

Baleiras-Couto MM, Reizinho RG, Duarte FL (2005) Partial 26S rDNA restriction analysis as a tool to characterize non-Saccharomyces yeasts present during red wine fermentations. Int J Food Microbiol 102:49-56

Barata A, Nobre A, Correia P, Malfeito-Ferreira M, Loureiro V (2006) Growth and 4-ethylphenol production by the yeast Pichia guilliermondii in grape juices. Am J Enol Viticult 57:133-138

Baro R, Maye M, Merida J, Medina M (1997) Changes in phenolic compounds and browning during biological aging of sherry-type wine. J Agric Food Chem 45:1682-1685

Caspritz G, Radler F (1983) Malolactic enzyme of Lactobacillus plantarum purification, properties and distribution among bacteria. J Biol Chem 258:4907-4910
Ciolfi G, Favale S, Pietromarchi P (2012) Production of volatile compounds by mixed cultures of Pichia guilliermondii and Saccharomyces cerevisiae. Vitis 51:191-194

Corona O, Squadrito M, Borsa D, Di Stefano R (2010) Behaviour of some compounds with $\lambda_{\max }$ at $280 \mathrm{~nm}$ in the determination of total flavonoids of grape skin extracts made from a hydroalcoholic $\mathrm{SO}_{2}-$ rich solvent. Ital J Food Sci 22:347-351

D.P.R. 17 (1987) Disciplinare di produzione della denominazione di origine controllata del vino «Marsala». Gazzetta Ufficiale. n. 163 del 15 luglio 1987

De Vuyst L, Tsakalidou E (2008) Streptococcus macedonicus, a multifunctional and promising species for dairy fermentations. Int Dairy $\mathrm{J}$ $18: 476-485$

Di Stefano R (1980) Gli alcoli superiori nei vini: influenza della cultivar e dell'annata di produzione. VigneVini 7:45-47

Di Stefano R (1983) Identification of ethyl esters of 2-hydroxyglutaric acid and 2-hydroxyglutaric acid g-lactone in wines. Vitis 22:220 224

Di Stefano R, Cravero CM (1992) The separation of hydroxycinnamates in wine. Sci Aliment 12:139-144

EEC (1990) Commision regulation n. 2676/90 determining community methods for the analysis of wine. Official J. Eur. Communities n. $267 / 30$

Esteve-Zarzoso B, Belloch C, Uruburu F, Querol A (1999) Identification of yeasts by RFLP analysis of the 5.8S rRNA gene and the two ribosomal internal transcribed spacers. Int J Syst Bacteriol 49:32337

Fleet GH (2003) Yeast interactions and wine flavor. Int J Food Microbiol $86: 11-22$

Fleet GH (2008) Wine yeasts for the future. FEMS Yeast Res 8:979-995

Francesca N, Chiurazzi M, Romano R, Aponte M, Settanni L, Moschetti G (2010) Indigenous yeast communities in the environment of "Rovello bianco" grape variety and their use in commercial white wine fermentation. World J Microbiol Biotechnol 26:337-351

Francis IL, Newton JL (2005) Determining wine aroma from compositional data. Aust J Grape Wine Res 11:114-126

Garcìa-Parrilla MC, Heredia FJ, Troncoso AM (1999) Sherry wine vinegars: phenolic composition changes during aging. Food Res Int 32: 433-440

Garcı-Ruiz A, Bartolome B, Cueva C, Martın-Alvarez PJ, MorenoArribas MV (2009) Inactivation of oenological lactic acid bacteria (Lactobacillus hilgardii and Pediococcus pentosaceus) by wine phenolic compounds. J Appl Microbiol 107:1042-1053

González SS, Barrio E, Querol A (2007) Molecular identification and characterization of wine yeasts isolated from Tenerife (Canary Island, Spain). J Appl Microbiol 102:1018-1025

Granchi L, Guerrini S, Vincenzini M (2005) I batteri lattici e la fermentazione. In: Vincenzini M, Romano P, Farris GA (eds) Microbiologia del vino. Milano, Casa Editrice Ambrosiana, pp 277-288

Guzzon R, Settanni L (2009) Brettanomyces/Dekkera, monitoraggio microbiologico e gestione in cantina. VigneVini 36:90-97

Guzzon R, Widmann G, Settanni L, Malacarne M, Francesca N, Larcher R (2011) Evolution of yeast populations during different biodynamic winemaking processes. S Afr J Enol Vitic 32:242-250

Huert Diaz-Reganon MD (1996) Evaluacion de parametros para la diferenciacion de vinos de la comunidad autonoma de Madrid. $\mathrm{PhD}$ dissertation University de Alcala de Henares, Madrid

ISO (International Standard Organization) (2004) Microbiology of food and animal feeding stuff. Horizontal methods for sampling techniques from surfaces using contact plates and swabs. Geneve, Switzerland

Le Jeune C, Enry C, Demuyter C, Lollier M (2006) Evolution of the population of Saccharomyces cerevisiae from grape to wine in a spontaneous fermentation. Food Microbiol 23:709-716 
Legras JL, Karst F (2003) Optimisation of interdelta analysis for Saccharomyces cerevisiae strain characterization. FEMS Microbiol Lett 221:249-255

Lopez I, Lopez R, Santamaria P, Torres C, Ruiz-Larrea F (2008) Performance of malolactic fermentation by inoculation of selected Lactobacillus plantarum and Oenococcus oeni strains isolated from Rioja red wines. Vitis 47:123-129

Nisiotou AA, Nychas GJE (2007) Yeast populations residing on healthy or Botrytis-infected grapes from a vineyard in Attica, Greece. Appl Environ Microbiol 73:2765-2768

Nurgel C, Pickering G (2005) Contribution of glycerol, ethanol and sugar to the perception of viscosity and density elicited by model white wines. J Texture Stud 36:303-323

O'Donnell K (1993) Fusarium and its near relatives. In: Reynolds DR, Taylor JW (eds) The fungal anamorph: mitotic, meiotic and pleomorphic speciation in fungal systematic. CAB International, Wallingford, pp 225-233

Ocón E, Garijo P, López R, Santamaría P (2010) Presence of nonSaccharomyces yeasts in cellar equipment and grape juice during harvest time. Food Microbiol 27:1023-1027

Ocón E, Garijo P, Sanz S, Olarte C, López R, Santamaría P, Gutiérrez AR (2013) Analysis of airborne yeast in one winery over a period of one year. Food Control 30:585-589

Oliveira JM, Sá MFF, Barros F, Araújo IM (2003) $\mathrm{C}_{6}$-alcohols as varietal markers for assessment of wine origin. Anal Chim Acta 563:300 309

Radeka S, Lukic I, Persuric D (2012) Influence of different maceration treatments on the aroma profile of rosé and red wines from Croatian aromatic cv. muskat ruza porecki (Vitis vinifera L.). Food Technol Biotechnol 50:2-53

Radin L, Pronzato C, Casareto L, Calegari L (1994) Tartaric acid in wines may be useful for preventing renal calculi: rapid determination by HPLC. J Liq Chromatrogr 17:2231-2246

Renouf V, Claisse O, Lonvaud-Funel A (2005) Understanding the microbial ecosystem on the grape berry surface through numeration and identification of yeast and bacteria. Aust J Grape Wine Res 11:316-327

Ribéreau-Gayon P, Dubordieu D, Donèche B, Lonvaud, A (2003) La natura chimica, l'origine e le conseguenze dei principali difetti organolettici. In: Ribéreau-Gayon P, Dubordieu D, Donèche B, Lonvaud A. (eds) Trattato di enologia. Edagricole, Bologna, pp 225-235

Rodriguez AV, Manca de Nadra MC (1995) Production of hydrogen peroxide by Lactobacillus hilgardii and its effect on Leuconostoc oenos growth. Curr Microbiol 30:23-25

Rojo-Bezares B, Sáenz Y, Navarro L, Zarazaga M, Ruiz-Larrea F, Torres C (2007) Coculture-inducible bacteriocin activity of Lactobacillus plantarum strain $\mathrm{J} 23$ isolated from grape must. Food Microbiol 24: 482-491

Salgues M, Cheynier V, Gunata Z, Wylde R (1986) Oxidation of grape juice 2-s-glutathionyl caffeoyl tartaric acid by Botrytis cinerea laccase and characterization of a new substance: 2,5-di-sglutathionyl caffeoyl tartaric acid. J Food Sci 51:1191-1194

Settanni L, Di Grigoli A, Tornambè G, Bellina V, Francesca N, Moschetti G, Bonanno A (2012a) Persistence of wild Streptococcus thermophilus strains on wooden vat and during the manufacture of a traditional caciocavallo type cheese. Int J Food Microbiol 155:73-81

Settanni L, Sannino C, Francesca N, Guarcello R, Moschetti G (2012b) Yeast ecology of vineyards within Marsala wine area (western Sicily) in two consecutive vintages and selection of autochthonous Saccharomyces cerevisiae strains. J Biosci Bioeng 114:606-614

Singleton VL, Timberlake CF, Lea AGH (1978) The phenolic cinnamates of white grapes and wine. J Sci Food Agric 29:403-410

Stackebrandt E, Goebel BM (1994) A place for DNA-DNA reassociation and 16S ribosomal-RNA sequence-analysis in the present species definition in bacteriology. Int J Syst Bacteriol 44:846-849

Suzzi G, Arfelli G, Schirone M, Corsetti A, Perpetuini G, Tofalo R (2012) Effect of grape indigenous Saccharomyces cerevisiae strains on Montepulciano d'Abruzzo red wine quality. Food Res Int 46:22-29

Tofalo R, Chaves-López C, Di Fabio F, Schirone M, Felis GE, Torriani S, Paparella A, Suzzi G (2009) Molecular identification and osmotolerant profile of wine yeasts that ferment a high sugar grape must. Int J Food Microbiol 130:179-187

Tofalo R, Schirone M, Corsetti A, Suzzi G (2012) Detection of Brettanomyces spp. in red wines using real-time PCR. J Food Sci 77:545-549

UNI 10957 (2003) Sensory analysis and method for establishing a sensory profile in foodstuffs and beverages

Urso R, Rantsiou K, Dolci P, Rolle L, Comi G, Cocolin L (2008) Yeast biodiversity and dynamics during sweet wine production as determined by molecular methods. FEMS Yeast Res 8:1053-1062

Valentao P, Seabra RM, Lopes G, Silva LR, Martins V, Trujillo ME, Velazquez E, Andrade P (2007) Influence of Dekkera bruxellensis on the contents of anthocyanins, organic acids and volatile phenols of Dao red wine. Food Chem 100:64-70

Vaudano E, Garcia-Moruno E (2008) Discrimination of Saccharomyces cerevisiae wine strains using microsatellite multiplex PCR and band pattern analysis. Food Microbiol 25:56-64

Vincenzini M, Romano P, Farris GA (2005) Microbiologia del vino. Casa Editrice Ambrosiana, Milano

Wang C, Liu Y (2013) Dynamic study of yeast species and Saccharomyces cerevisiae strains during the spontaneous fermentations of Muscat blanc in Jingyang, China. Food Microbiol 33:172-177

Weisburg W, Barns SM, Pelletier DA, Lane DJ (1991) 16S ribosomal DNA amplification for phylogenetic study. J Bacteriol 173:697-703

Wondra M, Boveric M (2001) Analyses of aroma components of Chardonnay wine fermented by different yeast strains. Food Technol Biotechnol 39:141-148

Zott K, Claisse O, Lucas P, Coulon J, Lonvaud-Funel A, MasneufPomarede I (2010) Characterization of the yeast ecosystem in grape must and wine using real-time PCR. Food Microbiol 27:559-567 